\title{
4 Transnational and migrant queer affects in two Basque films
}

\author{
Alfredo Martínez-Expósito \\ and Santiago Fouz-Hernández ${ }^{1}$
}

The recent coalescence of populism, nationalism, and xenophobia in a growing number of European countries is nurturing, at a scale rarely seen before, discourses that seek to legitimise, when not openly acclaim, anti-migrant and anti-queer ideologies. Queer migrants to - and within - this new Europe face the unpredictable behaviour of host communities that have been on many occasions shaped by the ambiguous rhetoric of homonationalism and the corporate and state practice of pinkwashing, and that almost invariably have internalised long-held prejudices about non-Western migrants. Stereotyping, labelling, and othering are just some of the attitudes, both social and individual, that queer migrants (as opposed to Western gay tourists) encounter - especially when their journey involves a transnational component. The huge emotional dimension of such journeys is quite often kept in silence and out of public sight as queer migrants (intersectionally vulnerable by virtue of their race, language, class or gender) are frightened or disconcerted in their new settings. In the intersection of the transnational, the emotional and the queer, a theory of migrant affects that acknowledges the central role of the body as a semiotic device may offer some provisional insights about the nature of transitional, in-flux identities.

The cinematic medium is particularly well positioned for the analysis of transnational queer emotions (Siu 2013; McGlotten 2013). The two films we analyse in this chapter are to some extent representative of Spanish cinema's sustained interest in migration (well documented in Santaolalla 2005; Ballesteros 2015), transnational identities (Dennison 2013), and queer narratives (see, for example, Melero 2010, 2017; Perriam 2013). As both a country of immigration and emigration within Europe and globally, Spain and some of its autonomous territories (the Basque Country and Catalonia most notably) are quite well versed in the dynamics of migrancy and the politics of cultural identity. Both Ander (2009, dir. Roberto Castón) and A escondidas/Hidden Away (2014, dir. Mikel Rueda) offer nuanced reflections about queer migrant subjects and their sexual/romantic relations in the Basque Country, following a thematic tradition that has produced other Spanish/Basque films such as lesbian narratives Habitación en Roma/Room in Rome (2010, dir. Julio Medem) and A mi madre le gustan las mujeres/ 
My Mother Likes Women (2002, dir. Féjerman and París), and the male gaythemed Los novios búlgaros/Bulgarian Lovers (2003, dir. Eloy de la Iglesia). The Basque setting of both Ander and A escondidas is a powerful reminder that the current wave of nationalism in many European countries (from xenophobic Hungary to populist Italy to post-Brexit referendum UK) had recent precedents in European territories such as Euskadi, where culture and language have been used to articulate forms of defensive nationalism. ${ }^{2}$

In these two Basque films queer migrants are deliberately positioned in a transnational journey that links their European (Basque) destination to their non-European origin, in ways that evidence the differential potential of their bodies and sexualities. Theories of affect are particularly useful in this context as they provide epistemological tools to seize the unseizable, nonverbal, bodily and corporeal aspects of the self. Moreover, as we argue in the analyses that follow, it is not only subjects/bodies and journeys but also geographies and locations that are queered in these films, often creating spatial alternatives to the city or 'the scene' for the expression of queer narratives. Crucially, these films make a strong case for the unsettling potential of transnational and migrant queer affects as they question and ultimately destabilise the rigid binarism that regulates the orthodox gender/ sexuality control system by complicating 'the binaries of the closet/coming out, shame/pride, and complicity/resistance' (Al-Samman and El-Ariss 2013: 206). The branch of affect theory represented by Brian Massumi considers affects as 'the capacity to affect and be affected' (Massumi 2015: 91). The uncompromising relational ontology thus invoked calls for an ethics of transitive and passive exchanges that resonates deeply with the queer politics of sexual migrants and dissidents: affect is not alien to questions of power just as power is never disconnected from affects. In other words, the field of the social - characterised by the pervasiveness of public and political interaction - becomes the primal scenario for both queer interactions and affective exchanges if we accept with Massumi that the latter are fundamentally relational, either in the transitive (to affect somebody) or in the passive sense (to be affected by somebody) - or, indeed, in permutations of the same formula, such as the mutual or the reciprocal (to affect each other, to affect one another). In this kind of relational ontology, there is not much space for intransitive or solipsistic theories of affect. This relational perspective is further supported by Sara Ahmed's brilliant image of affect's 'stickiness': 'affect is what sticks, or what sustains or preserves the connection between ideas, values, and objects' (Ahmed 2010b: 29). As the analysis of our films will reveal, the affective dimension of queer exchanges impregnates bodies and locations with a bonding sense of contestation that resonates particularly well with the 'affective turn' in cultural studies (Clough 2007). The aim of this chapter is to problematise, from an affective and bodily perspective, the transitional queer identities of Ander and A escondidas against the backdrop of an increasingly normalised and homonationalistic European milieu. 


\section{Transnational and migrant queer affects}

Queer affects provide a particularly privileged vantage point from which to observe the dissolution of the binaries that have been used traditionally to describe queer narratives. One of the most palpable remains of structuralism, binary thinking pervaded sexology and even queer theory in its beginnings. Any theory of affect that takes ineffability (the impossibility to translate affects into words) and embodiment seriously must come to acknowledge that gender dualism and its attendant binarisms of sexual orientation (homo/hetero), sexual practices (passive/active), body-gender identification (trans/cis), and sexual politics (closeted/out) are not only epistemologically limiting but also counterintuitive with regard to the lived experience of many individuals who do not recognise themselves in such a fabricated conceptual grid. Queer and affect theories coalesce to question the validity of pre-established normative categories: if queer approaches to identity seek to destabilise external, normative notions of identity, then theories of affect effectively deconstruct external, communal, communicable affects as approximate but ultimately inexact correlates of intimate, interior, bodily phenomena. The intersection of queer theory and theories of affect brings into relief the fact that embodied feelings and emotions are, too, a form of (queer) knowledge (as amply discussed in Sedgwick 2003; Ahmed 2004, 2006, 2014; or Butler 2015). These theoretical lineaments will be useful in reading the two proposed films as sites of resistance and contestation to received notions of transnational migrant queerness as they seek to naturalise queer affects beyond the existence of political or geographical borders while, concurrently, seeking to dilute the persistence of stereotyping and labelling and their by-products (which tend to simplify reality into facile binarisms such as good/bad, in/out, us/them, and the like).

Both Ander and A escondidas thematise affective transactions that cannot be fully apprehended by conventional geopolitics or acritical stereotyping. In both films, as we will see, some emotions are hardly expressed with words, sometimes because there are no apt words to express them (or are unknown to the characters); sometimes because the pragmatic situation of the characters renders words insufficient or inappropriate. Even naming these affects, emotions, and feelings becomes a futile exercise in basic nominalism, which the cinematic medium can avoid to some degree through the use of nonverbal cues (such as glances, silences or certain types of recurring shot). One of the major difficulties of approaching a study of (queer) affects in cinema is precisely the untranslatability of feelings and emotions into words. At its best, such an exercise is bound to reduce or even dissolve the complexity and singularity of the affective realm, thus betraying the ontology of what it tries to explain. To be clear about this point: the problem is not about applying Cartesian logic to a metaphysical object, but rather about using a proper code (language) to translate another code (film narrative) which evokes emotions in ways that are irreducible to linguistic formulae. 


\section{Triple marginalities/contested spaces}

As Isolina Ballesteros argues in her study of migration cinema in Europe, queer immigration films expose 'the double marginality that gay immigrants inhabit by being both immigrants . . . and gay' (Ballesteros 2015: 123). Our two case-studies are particularly good examples of this double marginality. In addition, the history of the Basque Country and, in the case of Ander, the rural and isolated setting add layers of marginalisation - and diversity - that complicate further the films' queer immigration discourses. Although some of these issues are beyond the scope of this chapter, it is relevant to note their affective potential. These overlapping levels of marginality and exclusion draw the local and immigrant queer characters of these films closer together in ways that both elicit affective readings of the films and enable a queer rethinking of space and (trans)national identity.

Ander places a considerable and very noticeable visual investment in the Basque countryside and the typical Basque caserio (stone farmhouse) where the protagonist's family lives. The long takes of the caserio that open and close the film function as visual bookends, and as a metaphor of apparent stasis and continuity despite the drastic reconfiguration of the family that inhabited it then and now. The presence of the rain at the end reinforces the cosiness of the new couple sharing a bed inside the house. In contrast, at the start of the film, middle-aged Ander (Josean Bengoetxea) and soonto-be-married sister Arantxa (Leire Ucha) live under the same roof as their overprotective and controlling widower mother (Pilar Rodríguez). A bad fall leaves Ander temporarily bedridden, forcing the family to hire the help of unassuming, Peruvian, transient farm worker José (Cristhian Esquivel). Later, during a walk around the farm's hilly surroundings, Arantxa asks José how different the landscape must be from his homeland. He responds that people keep asking him this but he finds the Basque scenery to be remarkably similar to 'home'. The casual comparison of the characteristically green and rugged Basque landscape in front of us to the imagined land of Peru, and the deceiving sense of stasis evoked by the exterior of the iconic caserio, illustrate what Rob Stone and Maria Pilar Rodríguez have identified as a distinctive feature of contemporary Basque cinema: a cinema in 'a context of flux instead of rigidity' that 'permits the transfer of social values from the cinema of citizens to the cinema of sentiment' (Stone and Rodríguez 2015: 9). Citing Anthony Giddens, they explain that this is possible when 'identity is no longer inherited, traditional or imposed but "discovered, constructed, actively sustained"' (Stone and Rodríguez 2015: 9). The important caserio bookends illustrate precisely this evolution. The meaning of 'family' evolves from one firmly rooted in tradition (both in terms of national identity and heteronormativity) to one that is as queer as it is transnational and constructed - not inherited. This change is symbolically marked by the film's setting at the turn of the century/millennium, a new beginning characterised by a relatively seamless continuity rather than drastic rupture. The foreboding presence of the millennium bug (in the news, in background 
conversations) is also highly symbolic: in the end, despite all the worries, the clock does not stop and life goes on.

Space is also affectively charged in our second case-study, A escondidas, set in the suburbs of the industrial city of Bilbao. The cosy family homes of the local teenage kids are contrasted with the cold, institutionalised, living environment of the foreign kids, a temporary facility for young asylum seekers that is at times shot from behind the fence, making it look like a prison. This contrast is further underscored symbolically in shared spaces like the nightclub or the swimming pool. A water polo match that should promote integration between local and foreign kids appears instead to encourage competitive rivalry by creating teams of 'locals' and 'visitors', as they are poignantly named on the score board. In the nightclub, the local kids avoid contact with a group of Moroccan kids. The Moroccans are reduced to the role of providing illegal substances to enhance the local boys' entertainment, but the locals won't allow them to mix with the local girls. As in Ander, the queer friendship and romance that emerges between the two boy protagonists, the local Rafa (Germán Alcarazu) and Moroccan Ibra (Adil Koukouh), defies this oppressive and prejudiced separation in an abundance of idyllic two-shots in spaces that are in themselves transitional and symbolic of border-crossing, such as a building site, fairground or train station (see Figure 4.1).

In short, space in both films is highly charged in ways that fuse issues of national and sexual identities affectively. The factory and the farm in Ander, or the school and the swimming pool in A escondidas, are first introduced as oppressive spaces that govern the regimented lives of the closeted local protagonists before being disrupted/awakened by the presence of the foreign other. In Ander, there is an underlying critique of the exodus of young people from the Spanish countryside to urban centres - what has recently become known as the 'España vaciada' (emptied Spain) - with entire villages now for sale on the global market. This critique is highly nostalgic. Ander's mother complains that most young people in the village have now moved to the industrial centres of Durango or Bilbao. One of the big challenges of the film is precisely whether one can be queer in a rural environment. A escondidas is a good reminder that urban centres have their own challenges in that respect. Age is another contributing factor here: it seems hard to come out when you are a middle-aged man living in a small rural community, but things are not much easier for teenagers struggling with their sexual identity and peer pressure from their classmates, even in a modern city almost two decades later (Ander is set in 1999, A escondidas in the 2010s).

Interestingly, none of the male protagonists in either film, local or immigrant, young or middle-aged, seems particularly defined by their sexual orientation. Despite the protagonists' not identifying or being easily identifiable as gay or queer, and thus also defying these pre-established categories and binary oppositions, there is a clear sense of social/sexual surveillance persistently performed by their family and friends. These repressive figures 


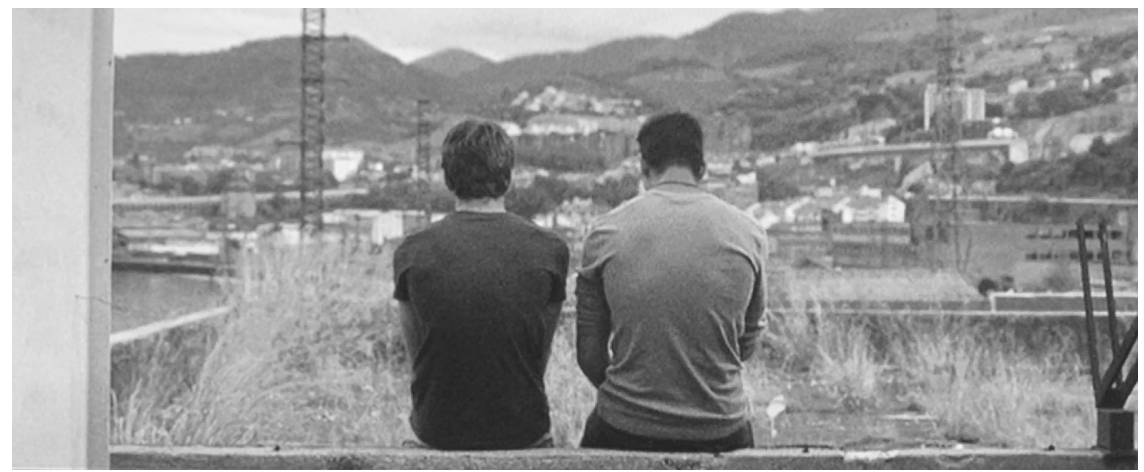

Figure 4.1 Rafa (Germán Alcarazu) and Ibra (Adil Koukouh) in A escondidas/Hidden Away (2014)

Source: A escondidas/Hidden Away (2014), directed by Mikel Rueda (C) Baleuko, Bitart New Media, Departamento de Cultura del Gobierno Vasco, Euskal Irrati Telebista, ICAA, MEDIA, and Filmrise (2017).

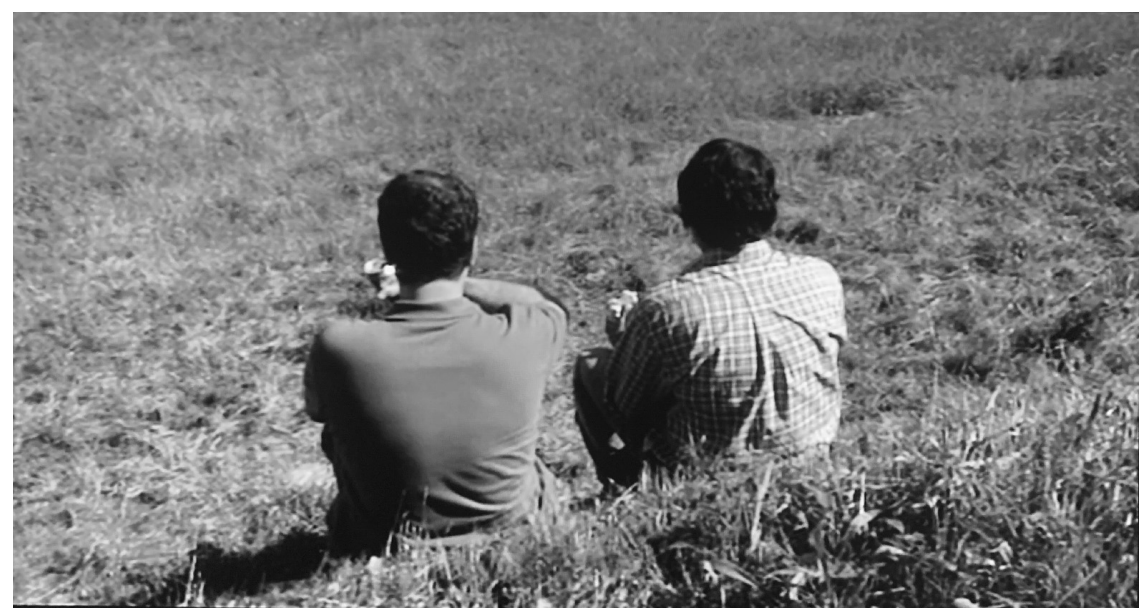

Figure 4.2 Ander (Josean Bengoetxea) and José (Cristhian Esquivel) in Ander (2009) Source: Ander (2009), directed by Roberto Castón ( Berdindu, Euskal Irrati Telebista, and Bodega Films (2010).

insist on asking Ander and Rafa if they have a girlfriend and even push them to pursue romance and sexual contact with women, be it the local prostitute Reme (Mamen Rivera) or Ander's former girlfriend Begoña in Ander, or Rafa's attractive classmate Marta (Garazi Navarro) in A escondidas. José's foreign 'otherness' does not free him from scrutiny either. As the sexual tension between him and his boss surreptitiously builds up, Ander's 
bullish friend Peio (Pako Revueltas) asks José directly if he likes women, forcing him to avert his eyes and assent, agreeing to a three-way sex, drinks and drugs party with Reme. In both films, the local protagonists' increasingly evident lack of interest in women leads to growing pressure from their inquisitive friends and family circles. These secondary characters are a constant reminder of the heteronormativity and compulsory heterosexuality that still permeates Spanish society at the turn of the 21 st century behind a façade of sexual permissiveness, arguably begun in the transition and culminating in 2005 with the legalisation of same-sex marriage which, as Gema Pérez-Sánchez has argued, was in part a propagandistic effort to modernise Spain's international image (Pérez-Sánchez 2010: 164).

In Ander, the use of Basque language amplifies national identity issues. Ander's Euskara-speaking mother adds an element of exclusion when the family welcomes José into their household (the lack of linguistic barriers is an important factor that attracts Latin American immigrants to Spain). She understands but cannot speak Spanish and relies on body language to communicate with the guest worker, largely ignoring him and demonstrating increasing levels of suspicion and aversion just as he and her son grow closer together. Yet both Arantxa and Ander communicate in Spanish with him, and the language barrier with the mother becomes a symbol of a generational divide rather than one of national identity: 'What do Peruvians even eat?' the mother asks as they prepare for José's arrival. It is as if she were about to confront a different species. Ander also uses language as a power tool in his relationships: he won't allow his mother's secret lover Evaristo (Pedro Otaegi) to call him Andrés (the Spanish version of his name), but insists that José call him by his name and not address him as 'boss'.

It is worth noting that both Ander and A escondidas also problematise the issue of regional/national identities and languages through the introduction of non-Basque characters and elements of the two other historic regions in Spain (Galicia and Catalonia). In A escondidas, the soundtrack (predominantly in English) includes a song in Catalan ('De bosc II' by Pau Vallvé), given prominence during the end credits. In Ander, the prostitute Reme hails from a coastal village in Galicia (poignantly called Cariño which translates as 'fondness', 'love' - she had to become a prostitute to care for her son, after her husband abandoned them). The final reconfiguration of the family in the caserio defies prejudices about sexual and national identities. A drunken Peio offensively but also transparently sums up his views on this new and unexpected scenario: 'what a trio: two fags and a whore'. Yet Peio is depicted as the loser here - an abusive, intoxicated and out-of-touch womaniser cuts a lonely figure, in contrast with José, Ander, and Reme, dignified and united by their otherness.

\section{The (wounded) queer body}

There is a tendency in contemporary mainstream Spanish films dealing with immigration to exoticise and sexualise the foreign other. ${ }^{3}$ Indeed, from the 
moment Ibra and José appear on the screen (at the very start of the film in the case of Ibra) their bodies take centre-stage. In A escondidas, with the help of the rain that creates a wet t-shirt effect, Ibra's fit body is introduced to the audience in an alluring medium close-up. Wardrobe and editing here contribute to make a spectacle of his body while at the same time the composition displaces him to the side of the screen, with the Basque countryside gradually out of focus behind him in an evocative mise-en-scène. In Ander, José is fully clothed and very inconspicuous when he is first introduced to the family (and the audience), but he is later seen working with his shirt unbuttoned, sweating and glistening as a result of the heat and physical labour. His body is also objectified in other ways. Ander seems obsessed with his very white teeth from the first time he meets him, commenting on them and checking them as if he were about to purchase a farm animal. The very nature of his work means that the family's main interest in him is his physical strength and ability to carry out demanding physical work. His gradual assimilation into Basque society and acceptance into the family is marked by an invitation to Arantxa's wedding, but also by a physical transformation when he wears Ander's dead father's suit for the event (at Ander's request). José wears the suit during the only sex scene with Ander, thus adding obvious potential for a psychoanalytical reading. In a highly symbolic gesture, José will eventually also take the father's old place at the dining table, something that had been explicitly forbidden by the mother for everyone except Ander.

What is different and distinctive about these two films is that the bodies of the Spaniards are also explicitly problematised and objectified. Mirrors play an important role in Ander and Rafa's physical depictions. In Part I of the film, Ander checks out his ageing body in the bedroom mirror as part of his evening routine while drying off after a shower. José appears in that exact same medium-long profile shot, repeating the same action some 20 minutes later in Part II. These recurring mirror shots also literally mirror each other. The composition is interesting in that it places the characters right at the centre of the frame, capturing the spectator's gaze and suggesting a sense of belonging. These shots not only anticipate the compatibility of the two male characters in a highly affective way (later enhanced with a number of two-shots), but also, in their similarity, imply that, like the Basque and the Peruvian countryside, these two men have more in common than may appear. In $A$ escondidas, Rafa uses the mirror to practise snogging as instructed by a friend in preparation for kissing classmate Marta. The resulting image, used as a publicity still and in the film trailer, is highly narcissistic but also homoerotic, again anticipating a kiss not with Marta but with Ibra later in the film.

Ander's body is used as a canvas to problematise and question the very idea of hegemonic masculinities, originally coined by R. W. Connell in the North American context in the 1990s and revised since then by her and Messerschmidt in the mid-2000s, and again more recently by Messerschmidt in a 
global context (see Connell 1995; Connell and Messerschmidt 2005; Messerschmidt 2008, 2012). Despite the physical nature of his work on the farm (and partly in the factory), Ander's body defies ideal standards of masculinity not only because of his ordinary, ageing physique, but also because it is injured and penetrated. There are unapologetic full-frontal scenes and, importantly, a notable long shot where his body is seen from behind. In a desperate attempt to restore a masculine and especially heterosexual identity following his first sexual encounter with José, Ander organises a trip with Reme and José but is unable to get aroused by her. Unable to perform sexually with a woman (undoubtedly with José in his mind), he gets hopelessly drunk in the hotel room. The mise-en-scène presents a chaotic picture of someone literally losing control of his body, fully naked and face-down in bed. Importantly, the fall that causes his injury early on in the film led to the arrival of José, whose job would be not only to tend to the farm but also to physically support Ander during his recovery. This arrangement creates unusual situations as José will have to lift and carry Ander from behind, giving the impression that he is about to fuck him (as he will indeed eventually do).

The trope of the wounded male body is particularly symbolic here, since 'limping' in Spanish is used as a metaphor for being gay (like 'maricón' queer - it used to be a pejorative term but has been reclaimed as a symbol of pride). ${ }^{4}$ This is further symbolised in the film with the figure of a lame pig that José is asked to slaughter. Surprised by the timing of the event (out of season), he realises (and checks) that he will be killing 'the lame pig'. Ander jokes that he hopes José 'does not mean him'. The equation of the wounded male body with homosexuality is another known trope in cultural representations of gay men, not uncommon in Spanish cinema, sometimes, as here and also in Gerardo Vera's Segunda piel/Second Skin (1999), enabling a same-sex relationship (a doctor and his patient in the case of Segunda piel). ${ }^{5}$ The same strategy is used in A escondidas, except in this case it is the Moroccan boy who is injured - also on the leg and also causing him to limp. The scene is symbolic in two important ways: it happens immediately after the men's first intimate encounter (thus reinforcing the sexual connotations of Rafa lovingly cleaning Ibra's bleeding wound), and the injury hinders Ibra's escape on the very night when he is forced to run away.

\section{Silences, glances and interruptions}

Despite this visual emphasis on the body and, in the case of Ander, perhaps inevitable comparisons with Ang Lee's Brokeback Mountain (2005, USA) (leading one reviewer to refer to the film ironically as 'BrokeBasque Mountain' (Huddleston 2009)), sexual contact between the two male protagonists is extraordinarily infrequent in both films, with only one sex scene between men in Ander and a playful embrace with interrupted kiss in A escondidas. ${ }^{6}$ Instead, the films rely on nervous glances and silences which, on the one 
hand, seem unusual in the context of contemporary LGBTIQ+ cinema in Spain and Spanish cinema more generally, but, on the other, fit a pattern of interrupted and frustrated sex between men in Spanish films of the last four decades or so. ${ }^{7}$ For example, the voice of Ander's mother checking if he's ok interrupts and frustrates his first post-fall masturbation in the shower. Later we find out from Reme that at the party that Peio organised with her and the two other men Ander could not take his eyes off José. On that occasion, following the classic love triangle pattern identified by Eve Kosofsky Sedgwick in her queer readings of the Anglo-American literary canon (see Sedgwick 1985), it could be argued that Reme's body functioned as mediator of the repressed sexual desire between the Basque and Peruvian men; but it could also be said that she was an involuntary obstruction.

The sex scene between Ander and José in the urinal at his sister's wedding is not interrupted by anyone but is very rushed and overshadowed by a sense of anxiety, since anyone could just walk in. Indeed, the tense, threeminute sex scene comes to a sudden end when Ander, overwhelmed by the situation, does not seem to ejaculate but instead throws up and pushes José away in apparent disgust at what has happened. In A escondidas, Rafás kiss on the mirror, also in the bathroom, is similarly interrupted by a phone call, and his first and only kiss with Ibra is also frustrated by Rafa's friends who unexpectedly erupt in the garage used as a games room where Rafa was hiding him. Earlier, in an apparent dream sequence, that kiss was also interrupted by the alarm clock which wakes him up. The title $A$ escondidas (better translated into English as 'gone into hiding') highlights the double marginality that it refers to: these young characters have to go into hiding to avoid Ibra's repatriation but also to live out their secret queer romance (see Ballesteros 2015). When they are caught just about to kiss, one of Rafa's friends sums this up quite well when he says that if Rafa is going to do that, he could at least do it with someone of his own 'species'. The implication here is that Western societies will now accept queerness more readily than interracial sex. The scene thus also illustrates the concept of homonationalism discussed in the first section of this chapter.

Although the relative lack of on-screen sexual contact between the male characters is, in part, disappointing, it is somewhat compensated for by a number of strategies that, crucially in the context of this chapter, construct their relationship affectively and in ways that serve to implicate the queer spectator through a) an insistent and harmonious visual pairing in both films, b) a series of intensively charged gazes and embraces, and c) an emphasis on the haptic image.

Visually, the frequent use of the two-shot (usually in medium shots) makes the central same-sex couples occupy most of the frame in a way that actively invites the spectator to sympathise with them and get closer to their feelings, their faces appearing in close-up at crucial moments of intimacy. In the mise-en-scène, the characters inhabit the space around them in clear harmony - both with each other and with the space - in sometimes unexpected 
but highly symbolic ways. In Ander, two of the scenes that mark the growing compatibility between the two men significantly involve José occupying the same space under a tree that Arantxa had told him Ander used for his lunch break. This recurring shot is then used in the two mirror scenes in the bedrooms already commented on. Later, Ander and José sit next to each other during a break (see Figure 4.2). The clear visual harmony of the scene, enhanced by their joyful facial expressions, is temporarily disturbed when Peio enters the frame, but immediately restored when he exits it. Although Ander and José meet each other for the first time in Ander's room while he is still bedridden, their only sex scene is, as discussed, while standing up in a urinal. The urinal is, as Chris Perriam notes in his own analysis of Ander, not uncommon 'for a gay drama' (Perriam 2013: 59), but toilets, also used in A escondidas as a place of sexual curiosity for Rafa, have a very long history for gay male sexual encounters, thus implicating specially older gay male spectators through their own memories associated with these spaces and encouraging their affective involvement with the scene. Just as the cold, empty and transitionary spaces symbolise the precarious and isolating nature of these transnational queer relationships, the optical compatibility between the characters and the way in which they inhabit meaningful spaces inject a certain sense of optimism into these exceptional love stories.

Many of the examples used in the two previous sections of this chapter are also illustrations of the haptic image. Ibra's soaked t-shirt at the start of $A$ escondidas, Rafa's kiss in the mirror, or, in Ander, the scenes that show José and Ander occupying the same spaces separately and at different times, are part of an effort to make the spectator sense their bodies and become emotionally involved with the characters, to the point of inhabiting those spaces. The same could be said about symbolic spaces and places like the empty dining table chair or the lunchbreak tree in Ander (spaces not coincidently associated with meal times, taste, smell and nurturing), or the empty pool and train station at the end of $A$ escondidas. These are sites of loss and nostalgia that Laura U. Marks has defined as having 'a sense of aura, that is, the marks of a long-gone living presence' (Marks 2002: 132). In Ander, the absent father (and later the absent sister and mother) are quite literally replaced by Reme, her son, and José. In A escondidas, Rafa is left only with half of the amulet that Ibra gave him. Symbolically, the amulet has two parts that, in Ibra's words, must always be joined together and eventually reunite if they ever become separated (Ibra took the other part when he realised the inevitability of their looming separation). Beyond the associations with primitivism evoked by the object - which could be stereotypically linked to Morocco - the amulet also has sexual connotations. It's the fetish that will come to embody both racial otherness and queerness. In the final moments of the film, Rafa touches it nostalgically and pensively, almost kissing it while he wipes the tears off his face, completely disconnected from the classroom. This emphasis on touching, like the focus on smelling, sobbing and vomiting in the toilet sex scene in Ander, is part of the films' haptic narrative that, as Marks 
has explained, enables a closeness between the spectator and the image which is prevented in optical distant vision. When this happens, she adds, 'we cannot help but be changed in the process of interacting' (Marks 2002: xvi).

Both Ander and A escondidas are filled with moments of the 'stickiness' that, as mentioned in our introduction, Ahmed sees in the nature of all affects: silent gestures, glances, recurring shots and visual motifs, haptic images that invite the spectator to draw unexpected connections between places and characters. These moments help to establish a dialogue between affects, bodies and locations, and to question (or at least shake up) dominant discourses of both queerness and migration. The 'affective turn' in cultural studies has been particularly aware of the role of place and location in relation to major affects such as trauma, shame, and happiness. As shown in our examples, places and locations are, from a transnational migrant queer perspective, rarely mere transitional throughways or non-spaces. By virtue of their own subjectivity, they become a semiotic conditioner of feelings and emotions, as much as feelings and emotions impregnate places and locations. While the films studied don't quite break the pattern of exoticising the body of the racial/foreign other, nor reverse the sense of sexual frustration (interruption) common in other LGBTIQ+-themed Spanish films, local and foreign male bodies here are quite literally - or at least cinematically - mirrored, thus destabilising rigid binarisms and gender/sexuality/race control systems observed in other mainstream Spanish films. In other words, transnational/ migrant queer affects in these films work as a subversive force that sticks, inviting the spectator to question and resist oppressive, dominant ideologies.

\section{Notes}

1 We dedicate this chapter to the memory of our esteemed late colleague, Lucille Cairns.

2 The Basque Country (or Euskadi in the Basque language) was one of the first Spanish territories to gain political autonomy with the 1978 Constitution. As was the case in other parts of Spain such as Galicia and Catalonia, the Basque Country's new autonomous powers favoured the expression of local cultures and languages which had been repressed during the 1939-1975 dictatorship. The years immediately before and after Franco's death (roughly 1973-1977), referred to in Spanish as la transición, were a time of intense political negotiation and deep social change which resulted in a relatively peaceful change of political regime: from a centralised, totalitarian, Catholic dictatorship to a decentralised, liberal, Western democracy. The Spanish transición was adversely affected by the 1973 international oil crisis and internal economic problems that generated important migratory waves, both nationally and abroad. In more recent times, far-right populism has surged in Spain. The far-right Vox party more than doubled its parliamentary representation from 24 seats in the April 2019 elections to 52 in the elections repeated in November of the same year.

3 We discuss this at some length in Fouz-Hernández and Martínez-Expósito (2007: 161-86).

4 See Martínez-Expósito (2000) for a study of the trope of the wounded male body in the context of Pedro Almodóvar's films. 
5 See Fouz-Hernández and Martínez-Expósito (2007: 111-34).

6 As will be clear to many readers by now, there are significant coincidences in plot between Ander and the later British film God's Own Country (2017, dir. Francis Lee), while $A$ escondidas is in some ways similar to the queer storyline of the recent BBC television series Years and Years (2019), created by Russell T. Davies.

7 See Fouz-Hernández (2017b) for further examples of this kind of interruption in contemporary Spanish cinema. 